\title{
Simultaneous overexpression of GH and STAT5b genes inhibits the STAT5 signalling pathway in tilapia (Oreochromis niloticus) embryos
}

\author{
Luis Fernando Marins ${ }^{2}$, Arati Iyengar ${ }^{1}$, Norman Maclean ${ }^{1}$, Jose A. Levy ${ }^{2}$ and Frédéric Sohm ${ }^{1}$ \\ ${ }^{1}$ School of Biological Sciences, Biomedical Sciences Building, University of Southampton, \\ Bassett Crescent East, Southampton, UK. \\ ${ }^{2}$ Fundação Universidade Federal do Rio Grande, Departamento de Química, \\ Laboratório de Bioquímica Marinha, Rio Grande, RS, Brazil.
}

\begin{abstract}
In this study, we describe the use of a STAT5 responsive element (LHRE) reporter gene to monitor the activity of the growth hormone $(\mathrm{GH})$ transduction pathway following expression of heterologous fish GH and rat STAT5b in tilapia embryos and fish fibroblast cells. Our results indicate that both GH and STAT5b are able to activate the LHRE at high levels when transferred separately, demonstrating the substantial level of conservation of the GH signal transduction pathways between fish and mammals. Unexpectedly, co-expression experiments show a strong inhibition of the GH-dependent activation, suggesting that simultaneous GH and STAT5b overexpression can counteract effects of $\mathrm{GH}$ expression in tilapia embryos.
\end{abstract}

Key words: teleost, growth hormone, signal transduction, cytokine, trangenesis signal transducers and activators of transcription.

Received: April 6, 2002; accepted: July 23, 2002.

\section{Introduction}

Growth is the result of complex molecular interactions in which growth hormone plays a major role in all vertebrates. Although the physiological effects of GH result from transcriptional regulation by several signalling pathways, the most direct involves the JAK/STAT signalling pathway (Moutoussamy et al., 1998). Fish GH receptor (GHR) cDNAs have been recently cloned and encode proteins of approximately 600 amino acids (Calduch-Giner et al., 2001; Lee et al., 2001). The GHR signal transduction follows a pattern shared amongst the receptors of the class I cytokine receptor superfamily. Briefly, the interaction of the hormone with the receptors induces receptor homodimerisation which in turn activates the GHR-associated Janus Kinase 2 (JAK2). The subsequent phosphorylation of the receptor tyrosines allows the recruitment of a class of highly related cytoplasmic proteins called signal transducers and activators of transcription or STATs. The GHRbound STATs are themselves phosphorylated by JAK2. Once phosphorylated, the cytoplasmic STATs form dimers, translocate into the nucleus where they bind to a palindromic DNA motif present in STAT inducible gene promoters and activate the transcription of target genes

Send correspondence to F. Sohm. Department of Biology and Biochemistry, University of Bath, Bath, BA2 7AY U.K. E-mail: bssfs@bath.ac.uk.
(Kopchick and Andry, 2000; Takeda and Akira, 2000). GH activates STAT1, STAT3 and STAT5 (Moutoussamy et al., 1998). In mammals, GH responsive elements have been identified within several gene promoters and some of them have been investigated using reporter genes (Sotiropoulos et al., 1996; Liu et al., 1997; Storz et al., 1999; von Laue et al., 2000; Ehret et al., 2001).

In fish, growth enhancement has been achieved by transgenic overexpression of GH in several lines, while no enhancement has been observed in others, including a recent report of lack of growth enhancement in genetically selected strains of trout (Du et al., 1992; Devlin et al., 1994; de la Fuente et al., 1999; Rahman and Maclean, 1999; Devlin et al., 2001). Additionally, better growth enhancement has been obtained with relatively low levels of circulating GH (de la Fuente et al., 1999). Even though several genes from the JAK/STAT signal transduction pathway have been identified in fish (Rycyzyn et al., 1998; Baudler et al., 1999; Oates et al., 1999a, 1999b; Leu et al., 2000), little is known about fish GH signal transduction pathways and just recently the GH receptor itself has been cloned in this group of vertebrates (Calduch-Giner et al., 2001; Lee et al., 2001).

In the present study, we describe the use of LHRE (lactogenic hormone responsive element), a STAT5 responsive element (Sotiropoulos et al., 1996) spliced to a luciferase reporter gene, to monitor the activation of the JAK/STAT signalling pathway in response to heterologous 
GH and STAT5b overexpression in fish embryos. To examine this question we have used vectors expressing the marine silverside (Odontesthes argentinensis) fish GH and the rat STAT5b. We show that the GH and the STAT5b are able to induce the expression of a luciferase gene under control of a STAT5 responsive element both in fish fibroblasts and tilapia embryos. Moreover, we show that the overexpression of both GH and STAT5b inhibits the expression of the LHRE element.

\section{Materials and Methods}

\section{Plasmids}

pP3PA-c $\beta A c t i n / l a c Z$ (hereafter referred to as $p c \beta A /$ lacZ) consists of the lacZ gene under the control of the carp $\beta$-actin promoter and $\mathrm{pCMV/STAT5b-GFP}$ expresses a STAT5b-GFP fusion protein under the control of the cytomegalovirus promoter (Alam et al., 1996; Herrington et al., 1999). pLHRE-TK/luc and pTK/luc consist of the luciferase gene under the control of the thymidine kinase minimal promoter with and without a six times repeat of the lactogenic responsive element respectively (Sotiropoulos et al., 1996). The $\mathrm{pc} \beta \mathrm{A} / \mathrm{msGH}$ was constructed by replacing the lacZ sequence of $\mathrm{pc} \beta \mathrm{A} / \mathrm{lacZ}$ by a $N c o \mathrm{I} / E c o R \mathrm{I}$ fragment containing the $\mathrm{cDNA}$ of the growth hormone gene of the marine silverside fish (Genbank/EMBL accession number AF236091). The insertion was confirmed by sequencing. The vector pP3PAc $\beta$ Acin/GFP was constructed as the $\mathrm{pc} \beta \mathrm{A} / \mathrm{msGH}$ but the cDNA coding for the green fluorescent protein was used instead of the msGH (S. Brooks, unpublished).

\section{Cell culture and transfections}

The BF-2 cell line (Bluegill sunfish fibroblasts, Ref. 87032603, ECACC, Bath, UK) were cultured in L-15 medium, supplemented with $10 \%$ foetal calf serum (ICN), $2 \mathrm{mM}$ glutamine (Sigma) and antibiotic/antimycotic solution (Sigma) at $26{ }^{\circ} \mathrm{C}$ without $\mathrm{CO}_{2}$. For transient transfection 300,000 cells per well (12-well plates) were seeded and incubated overnight. Transfections were performed at approximately $60 \%$ confluence using FuGENE 6 transfection reagent (Roche Molecular Biochemicals, UK). Prior to transfection, the cells were washed to remove the serum. For the transfection, $400 \mu \mathrm{L}$ of medium without serum plus $100 \mu \mathrm{L}$ of DNA-FuGENE 6 mixture were added to each well in all experiments. The total amount of DNA transfected per well was always $1 \mu \mathrm{g}$. Cells were incubated for $24 \mathrm{~h}$ at $26^{\circ} \mathrm{C}$ without $\mathrm{CO}_{2}$ and then analysed for luciferase expression.

The dose response experiment was carried out by transfecting increasing quantities of the $\mathrm{pc} \beta \mathrm{A} / \mathrm{msGH}$ construct (0 to $200 \mathrm{ng}$ ) together with the pLHRE-TK/luc reporter construct (330 ng), and pc $\beta \mathrm{A} / \mathrm{lacZ}$ (330 ng). The transfections were completed with the pc $\beta \mathrm{A} / \mathrm{GFP}$ construct to keep the amount of transfected DNA $(1 \mu \mathrm{g})$ constant. In order to confirm GH secretion into the medium, we also recovered, centrifuged and filtered the supernatant of BF-2 cells previously transfected with $\mathrm{pc} \beta \mathrm{A} / \mathrm{msGH}$ and utilised this to replace the medium of cells transfected without $\mathrm{pc} \beta \mathrm{A} / \mathrm{msGH}$. In a second set of experiments, in order to verify the effect of the heterologous STAT5b gene expression on the JAK/STAT signalling pathway in fish fibroblast cells, $100 \mathrm{ng}$ of the vector expressing the rat STAT5b (pCMV/STAT5b-GFP) were co-transfected with pLHRE$\mathrm{TK} / \mathrm{luc}$ and $\mathrm{pc} \beta \mathrm{A} / \mathrm{lacZ}$, with or without $\mathrm{pc} \beta \mathrm{A} / \mathrm{msGH}$ $(100 \mathrm{ng})$. For all these tests, control experiments with the pTK/luc instead of the pLHRE-TK/luc were carried out under the same conditions. Every transfection experiment was performed at least three times in triplicate.

\section{Tilapia egg microinjections}

Transgenic tilapias were generated by co-injecting $3 \times 10^{5}$ copies of $\mathrm{GH}$ expression vector $(\mathrm{pc} \beta \mathrm{A} / \mathrm{msGH})$ and either pLHRE-TK/luc or pTK/luc into the cytoplasm of one-cell stage fertilised eggs. A second experiment was carried out using STAT5b expressing vector instead of the GH expressing vector. Groups of embryos were injected with either pLHRE-TK/luc or pTK/luc and used as controls. Total DNA injected was kept at $10^{6}$ copies using $\mathrm{pc} \beta \mathrm{A} / \mathrm{GPF}$ whenever necessary. A total number of $562 \mathrm{em}-$ bryos were reared until hatching and immediately frozen in liquid nitrogen and stored at $-70{ }^{\circ} \mathrm{C}$ until the luciferase assay.

\section{Luciferase and $\beta$-Galactosidase assay}

The Luciferase Assay System (Promega, UK) was used to analyse both cells and tilapia embryos. Briefly, $24 \mathrm{~h}$ after transfection or $4 \mathrm{~h}$ after the change of medium, the cells were washed twice with PBS and lysed in $600 \mu \mathrm{L}$ of the $1 \mathrm{X}$ Cell Culture Lysis solution. $20 \mu \mathrm{L}$ of the lysate was transferred into scintillation vials and counted after addition of $100 \mu \mathrm{L}$ luciferin solution. The samples were measured in a liquid scintillation counter (LKB-Wallac). Frozen tilapia embryos were thawed at room temperature and homogenised in $300 \mu \mathrm{L}$ of $1 \mathrm{X}$ Cell Culture Lysis solution and $100 \mu \mathrm{L}$ of the lysate was used for counting.

$\beta$-Galactosidase assays were performed as described in Rahman et al. (2000). After normalisation of the luciferase activity by the $\beta$-Galactosidase activity in each well, data are presented as the mean fold-induction \pm S.E. Cell culture data were analysed using t-test, while the data for embryo were analysed using the Mann-Whitney U-test.

\section{Results and Discussion}

\section{Activation of the LHRE by msGH overexpression}

The new vector $\mathrm{pc} \beta \mathrm{A} / \mathrm{msGH}$ was tested by co-transfection experiments in fish fibroblast cells with the pLHRE-TK/luc reporter construct. As expected, increasing 
quantities of the $\mathrm{GH}$ expressing construct $\mathrm{pc} \beta \mathrm{A} / \mathrm{msGH}$ led to increased expression of the pLHRE-TK/luc in the BF-2 cells, while none of the $\mathrm{pc} \beta \mathrm{A} / \mathrm{msGH}$ concentrations tested affected the luciferase induction of the control pTK/luc vector (Figure 1a). A basal activity of STAT5 is likely to be present in BF-2 cells since luciferase expression was found to be higher in cells transfected with the LHRE reporter construct alone when compared to cells transfected with the pTK/luc (Figure 1b). The luciferase activity of the pLHRE-TK/luc increased steadily with transfected concentration of the $\mathrm{pc} \beta \mathrm{A} / \mathrm{msGH}$ construct up to a maximum of 13.5 fold induction. Further addition of the GH expressing construct reduced the LHRE-TK promoter induction thereafter. The bell-shaped activation curve suggests that, in fish as in mammals, STAT5b induction is dependent on dimerisation of the GH receptor (Ilondo et al., 1994). To demonstrate the secretion of the $\mathrm{msGH}$, cells were transfected without msGH but exposed for $4 \mathrm{~h}$ to the supernatant from cells transfected with $\mathrm{pc} \beta \mathrm{A} / \mathrm{msGH}$ ( 0 to $200 \mathrm{ng}$ DNA). This supernatant was indeed able to significantly induce luciferase expression to levels up to $70 \%$ of the $\mathrm{pc} \beta \mathrm{A} / \mathrm{msGH}$ transfected cell, $(\mathrm{p}<0.05$, $\mathrm{t}$-test, data not shown). This expression cannot be explained by leftover DNA/FuGENE 6 mixture in the supernatant since $4 \mathrm{~h}$ is not sufficient to observe any transfection in BF-2 cells (data not shown).

We next injected the $\mathrm{pc} \beta \mathrm{A} / \mathrm{msGH}$ construct together with the $\mathrm{pLHRE}-\mathrm{TK} / \mathrm{luc}$ into one-cell stage tilapia eggs. As shown in Figure 2, our results demonstrate a highly significant increase of luciferase induction (10.3-fold) in a group of fish co-injected with $\mathrm{pc} \beta \mathrm{A} / \mathrm{msGH}$ and $\mathrm{pLHRE}-\mathrm{TK} / \mathrm{luc}$ when compared to the control group $(\mathrm{p}<0.001$, Mann-Whitney U-test). Again, no significant induction of luciferase expression was observed in embryos injected with the pTK/luc vector. These observations are in agreement with the data obtained from ex vivo experiments and prove that the marine silverside $\mathrm{GH}$ driven by the carp $\beta$-actin promoter ( $\mathrm{pc} \beta \mathrm{A} / \mathrm{msGH})$ is able to induce the GH signalling pathway to high levels both in fish fibroblast cells and in tilapia embryos.

\section{Activation of the LHRE by rat STAT5b}

Overexpression of STAT5b induces a slight but significant increase in luciferase expression in LHRE-TK/luc transfected cells ( 1.4 -fold induction, $\mathrm{p}<0.05$, t-test, Figure $3 a)$. The overexpression of STAT5b in fish embryos produced a highly significant 10 -fold induction of luciferase over the control batches of injected embryos ( $p<0.001$, Mann-Whitney U-test, Figure 3b). This high level of induction observed in tilapia embryos suggests that rat STAT5b is activated by endogenous fish growth factors and is fully functional in fish. To the best of our knowledge, this is the first demonstration that a mammalian STAT5b is functional in a teleost. Taken together with the results on activa- tion of the JAK/STAT signal transduction pathway in mammalian cells by the tilapia prolactin receptor (Sohm et al., 1998) or the zebrafish STAT1 (Oates et al., 1999b),

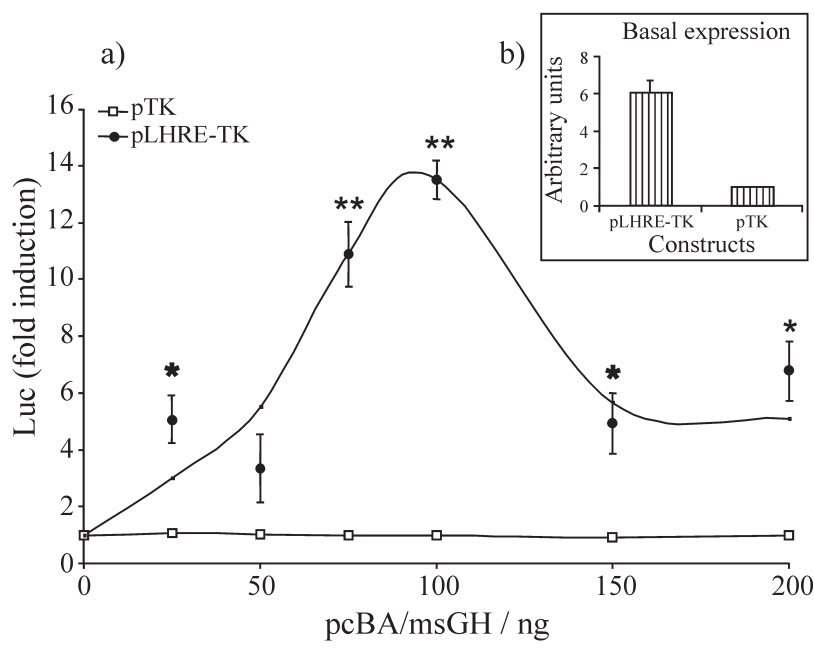

Figure 1 - a) Luciferase expression induced by increasing quantities of the $\mathrm{GH}$ expressing vector $(\mathrm{pc} \beta \mathrm{A} / \mathrm{msGH})$ in fish fibroblast cells co-transfected with a reporter vector with or without STAT5 responsive element (pLHRE-TK/luc or pTK/luc, respectively). Fold-induction corresponds to the ratio of the mean luciferase activity obtained at each point by the mean luciferase activity derived from the experiment where the appropriate reporter vector was transfected alone. b) Basal activity of pLHRE-TK/luc and pTK/luc in absence of hormone. The asterisks indicate the level of significant difference with the corresponding reporter vector transfected alone: $*=\mathrm{p}<0.05, * *=\mathrm{p}<0.01$, t-test, $\mathrm{n}=3$.

Tilapia embryos

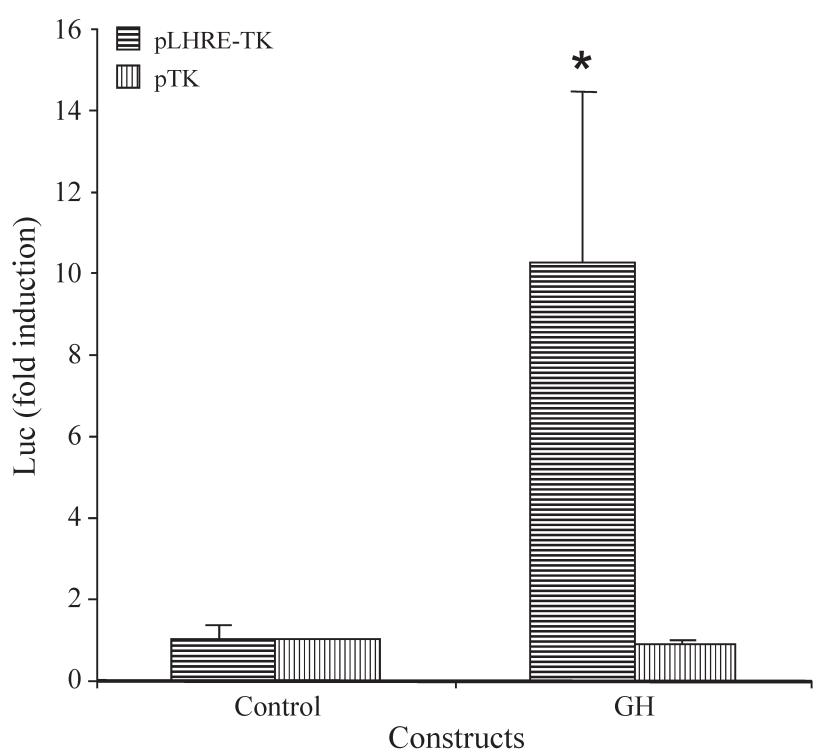

Figure 2 - Luciferase expression induced by the GH expressing vector in tilapia embryos. Control: pLHRE-TK/luc or pTK/luc vector injected alone. GH: $\mathrm{pc} \beta \mathrm{A} / \mathrm{msGH}$ was co-injected either with the pLHRE-TK/luc vector or the pTK/luc vector. Fold induction, see Figure 1. The asterisk indicates a significant difference with the group which was injected with the corresponding reporter vector alone: $*=p<0.001$, Mann-Whitney U-test, $\mathrm{n}=32$ to 78 . 


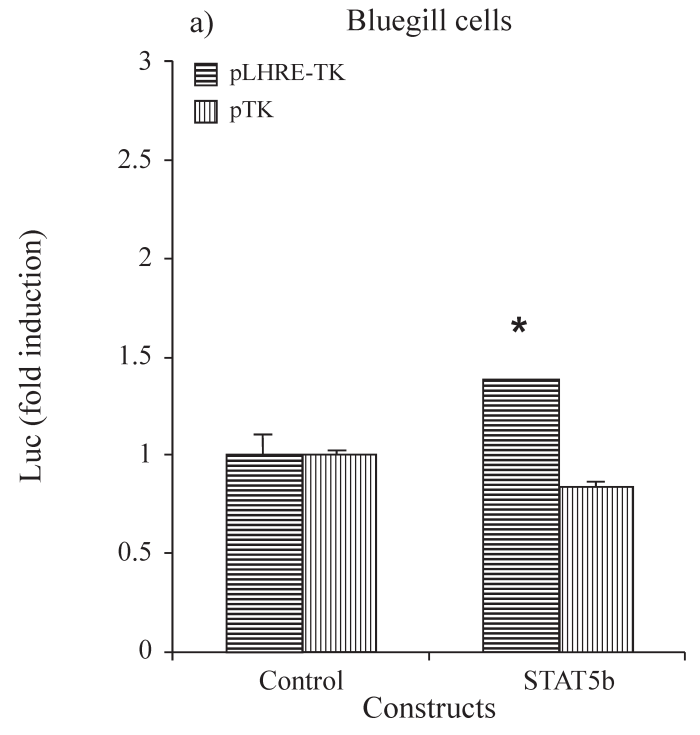

b) Tilapia embryos

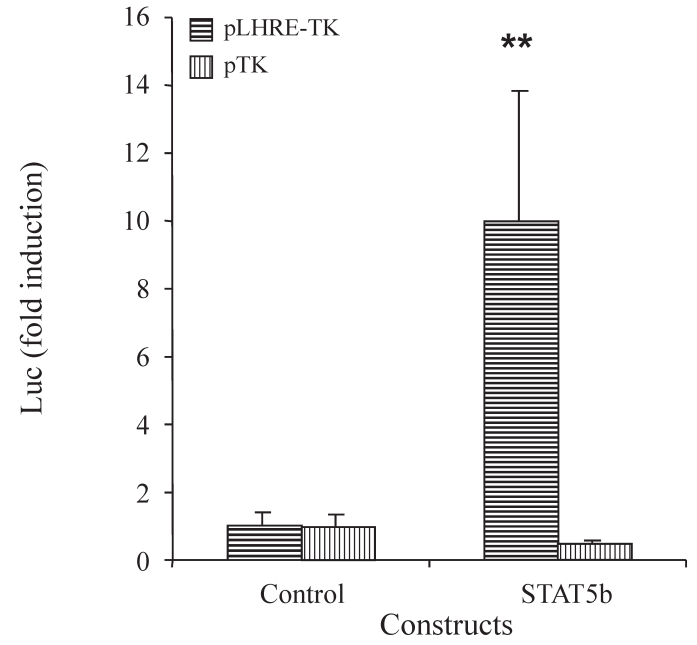

Figure 3 - Luciferase expression induced by the STAT5b expressing vector in fish fibroblast cells (a) and in tilapia embryos (b). Control: pLHRETK/luc or pTK/luc vector transfected alone. STAT5b: pCMV/STAT5b co-transfected with the pLHRE-TK/luc vector or the pTK/luc vector. The fold induction and asterisks are defined as in Figure 1. ${ }^{*}=\mathrm{p}<0.05$, t-test, $\mathrm{n}=3, * *=\mathrm{p}<0.001$, Mann-Whitney U-test.

these results indicate that JAK/STAT transduction pathways are remarkably similar in fish and in mammals, although we know now that the overall homology between teleost GHRs and GHRs of other species is in fact rather low ( $\approx 40 \%$ in aa identity; Calduch-Giner et al., 2001; Lee et al., 2001).

\section{Co-expression of msGH and STAT5b}

When the $\mathrm{pc} \beta \mathrm{A} / \mathrm{msGH}$ and $\mathrm{pCMV} / \mathrm{STAT} 5 \mathrm{~b}-\mathrm{GFP}$ constructs were co-transfected in BF-2 cells an induction of 2.4-fold over the pLHRE-TK/luc control ( $\mathrm{p}<0.01$, t-test) and 1.8-fold over STAT5b alone was observed, $(\mathrm{p}<0.05$, t-test), but there was a 5-fold inhibition of luciferase expression ( $\mathrm{p}<0.005$, t-test) when compared to the msGH transfected cells (Figure 4a). These results are in contrast to the observations made in mammalian fibroblasts where $\mathrm{GH}$ and STAT5a were found to act synergistically (von Laue et al., 2000). Interestingly, tilapia embryos co-injected with both GH and STAT5b expression vectors demonstrate an even stronger inhibition $(\approx 20 \mathrm{x})$ of the LHRE-TK/luc expression when compared to the $\mathrm{pc} \beta \mathrm{A} / \mathrm{msGH}$ injected embryos $(\mathrm{p}<0.001$, Figure $4 \mathrm{~b}$ ). In mammals, STAT5a/b interact and are regulated by several growth factors and hormones that can down regulate their signalling (Yoshimura, 1998; Favre-Young et al., 2000; von Laue et al., 2000). However, the most likely candidates for the down regulation of STAT5b signalling in the presence of GH are the suppressors of cytokine signalling or SOCS proteins which have been shown to regulate the signal transduction of GH receptors (Adams et al., 1998; Favre et al., 1999). Moreover, in mice, STAT5 is implicated in the
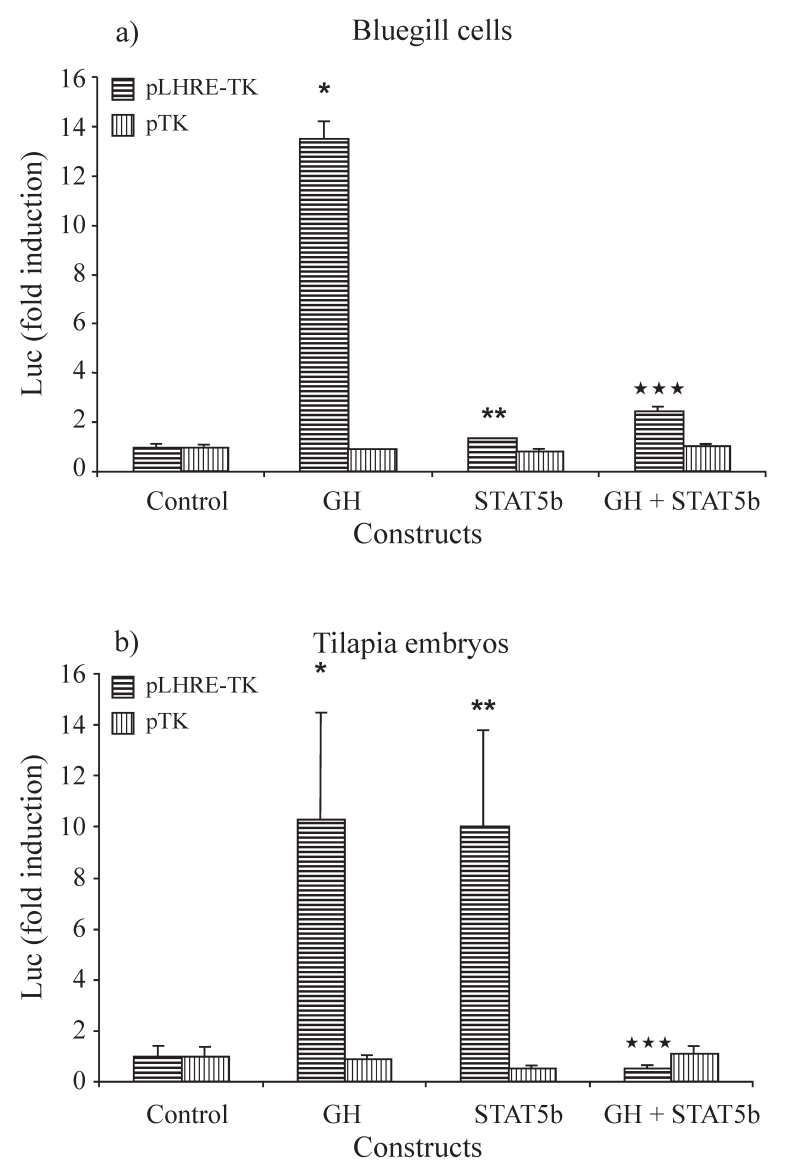

Figure 4 - Co-expression effects of the pc $\beta \mathrm{A} / \mathrm{msGH}$ and $\mathrm{pCMV} / \mathrm{STAT} 5 \mathrm{~b}$ constructs on the LHRE reporter gene in fibroblast cells (a) and fish embryos (b). Control: pLHRE-TK/luc or pTK/luc vector expressed alone. $\mathrm{pc} \beta \mathrm{A} / \mathrm{msGH}(\mathrm{GH})$ or $\mathrm{pCMV} / \mathrm{STAT} 5 \mathrm{~b}$ (STAT5b) were expressed either with the pLHRE-TK/luc vector or the pTK/luc vector. GH+STAT5b: co-expression of both $\mathrm{pc} \beta \mathrm{A} / \mathrm{msGH}$ and $\mathrm{pCMV} / \mathrm{STAT} 5 \mathrm{~b}$ with the reporter genes. Asterisks represent the level of significant difference of each expressing vector over $\mathrm{pLHRE-TK/luc,} \mathrm{while} \mathrm{stars} \mathrm{indicate} \mathrm{the} \mathrm{level} \mathrm{of} \mathrm{sig-}$ nificant difference of GH+STAT5b over pc $\beta \mathrm{A} / \mathrm{msGH}$. a) $*=\mathrm{p}<0.01$, t-test, $\mathrm{n}=3, * *=\mathrm{p}<0,05$, t-test, $\mathrm{n}=3, \star \star \star=\mathrm{p}<0.005$, t-test, $\mathrm{n}=3 . \mathbf{b})$ $*$, $* *$ and $\star \star \star=\mathrm{p}<0.001$, Mann-Whitney U-test, $\mathrm{n}=32$ to 78 . 
GH-dependent transcription of SOCS-3, which in turn inhibits GH ability to induce the transcription of the Spi 2.1 promoter (Adams et al., 1998). Our results clearly show that the overexpression of STAT5b can counteract effects of GH overexpression in fish, but the precise mechanism of this down regulation of STAT5 responsive elements by overexpressed-STAT5b remains to be clarified.

This down regulation of the $\mathrm{GH}$ signalling could have important consequence in fish. Recently, Devlin and collaborators have shown that in fast growing selected strains of trout, growth hormone overexpression frequently did not improve growth and could even have deleterious effects on the health of the fish (Devlin et al., 2001). It is likely that genetic selection may act to increase plasma GH levels but may also modify GH signal transduction pathways. In regard to our results, it is probable that GH-dependent STAT5 signal transduction pathways are at least partially responsible for the deleterious effects of GH overexpression observed in genetically selected fish.

At a time when increasing concern regarding transgenesis is being expressed, a proper understanding of the $\mathrm{GH}$ transduction pathway in fish is needed. The production of fish lineages carrying reporter gene constructs from the best characterised mammalian transduction signal pathways could already bring more understanding of GH transduction signal in fish. STAT responsive elements seem good candidates to start with and would allow further investigations of $\mathrm{GH}$, prolactin and cytokines transduction signal pathways in vivo in teleosts.

\section{Acknowledgements}

The authors wish to thank Dr. Christin Carter-Su (University of Michigan Medical School, Michigan, USA) and Dr. Li-yuan Yu-Lee (Baylor College of Medicine, Houston, USA) who kindly provided the pCMV/STAT5bGFP, Dr. Jöelle Finidori (Hôpital Necker-Enfants Malades, Paris, France) for the gift of the pLHRE-TK/luc and the pTK/luc plasmids, and Dr. Suzanne Brooks (University of Southampton, UK) for providing the plasmid pP3PAc $\beta$ Actin/GPF. We are also grateful to Rosemary Bell for her help with the scintillation counter. L.F. Marins was supported by a CAPES scholarship of the Brazilian Ministry of Education.

\section{References}

Adams TE, Hansen JA, Starr R, Nicola NA, Hilton DJ and Billestrup N (1998) Growth hormone preferentially induces the rapid, transient expression of SOCS-3, a novel inhibitor of cytokine receptor signaling. J Biol Chem 273:1285-1287.

Alam MS, Lavender FL, Iyengar A, Rahman MA, Ayad HH, Lathe R, Morley SD and Maclean N (1996) Comparison of the activity of carp and rat b-actin gene regulatory sequences in tilapia and rainbow trout embryos. Mol Reprod Dev 45:117-122.
Baudler M, Schartl M and Altschmied J (1999) Specific activation of a STAT family member in Xiphophorus melanoma cells. Exp Cell Res 249:212-220.

Calduch-Giner J, Duval H, Chesnel F, Boeuf G, Perez-Sanchez J and Boujard D (2001) Fish growth hormone receptor: molecular characterization of two membrane-anchored forms. Endocrinology 142:3269-3273.

de la Fuente J, Guillén I, Martínez R, and Estrada MP (1999) Growth regulation and enhancement in tilapia: basic research findings and their applications. Genet Anal 15:85-90.

Devlin RH, Biagi CA, Yesaki TY, Smailus DE and Byatt JC (2001) Growth of domesticated transgenic fish. Nature 409:781-782.

Devlin RH, Yesaki TY, Biagl CA, Donaldson EM, Swanson P and Chan W-K (1994) Extraordinary salmon growth. Nature 371:209-210.

Du S-J, Gong Z, Fletcher GL, Shears MA, King MJ, Idler DR and Hew CL (1992) Growth enhancement in transgenic Atlantic salmon by the use of an "all fish" chimeric growth hormone gene construct. Bio-Technol 10:176-181.

Ehret GB, Reichenbach P, Schindler U, Horvath CM, Fritz S, Nabholz M and Bucher P (2001) DNA binding specificity of different STAT proteins: comparison of in vitro specificity with natural target sites. J Biol Chem 276:6675-6688.

Favre H, Benhamou A, Finidori J, Kelly PA and Edery M (1999) Dual effects of suppressor of cytokine signaling (SOCS-2) on growth hormone signal transduction. FEBS Lett 453:63-66.

Favre-Young H, Dif F, Roussille F, Demeneix BA, Kelly PA, Edery M and de Luze A (2000) Cross-talk between signal transducer and activator of transcription (Stat5) and thyroid hormone receptor- $\beta 1$ (TR $\beta 1)$ signaling pathways. Mol Endocrinol 14:1411-1424.

Herrington J, Rui L, Luo G, Yu-Lee L and Carter-Su C (1999) A functional DNA binding domain is required for growth hormone-induced nuclear accumulation of Stat5b. J Biol Chem 274:5138-5145.

Ilondo MM, Damholt AB, Cunningham BA, Wells JA, Meyts P and Shymko RM (1994) Receptor dimerization determines the effects of growth hormone in primary rat adipocytes and cultured human IM-9 lymphocytes. Endocrinology 6:23972403.

Kopchick JJ and Andry JM (2000) Growth hormone (GH), GH receptor, and signal transduction. Mol Genet Metab 71:293314.

Lee LT, Nong G, Chan YH, Tse DL and Cheng CH (2001) Molecular cloning of a teleost growth hormone receptor and its functional interaction with human growth hormone. Gene 270:121-129.

Leu JH, Yan SJ, Lee TF, Chou CM, Chen ST, Hwang PP, Chou CK and Huang CJ (2000) Complete genomic organization and promoter analysis of the round-spotted pufferfish JAK1, JAK2, JAK3, and TYK2 genes. DNA Cell Biol 19:431-446.

Liu N, Mertani HC, Norstedt G, Törnell J and Lobie PE (1997) Mode of the autocrine/paracrine mechanism of growth hormone actions. Exp Cell Res 237:196-206.

Moutoussamy S, Kelly PA and Finidori J (1998) Growthhormone-receptor and cytokine-receptor-family signaling. Eur J Biochem 5:1-11.

Oates AC, Brownlie A, Pratt SJ, Irvine DV, Liao EC, Paw BH, Dorian KJ, Johnson SL, Postlethwait JH, Zon LI and Wilks 
AF (1999a) Gene duplication of zebrafish JAK2 homologs is accompanied by divergent embryonic expression patterns: only jak2a is expressed during erythropoiesis. Blood 94:2622-2636.

Oates AC, Wollberg P, Pratt SJ, Paw BH, Johnson SL, Ho RK, Postlethwait JH, Zon LI and Wilks AF (1999b) Zebrafish stat 3 is expressed in restricted tissues during embryogenesis and stat1 rescues cytokine signaling in a STAT1-deficient human cell line. Dev Dynam 215:352-370.

Rahman MA, Hwang G-L, Razak SA, Sohm F and Maclean N (2000) Copy number related transgene expression and mosaic somatic expression in hemizygous and homozygous transgenic tilapia (Oreochromis niloticus). Transgenic Res 9:417-427.

Rahman MA and Maclean N (1999) Growth performance of transgenic tilapia containing an exogenous piscine growth hormone gene. Aquaculture 173:333-346.

Rycyzyn MA, Wilson MR, Bengten E, Warr GW, Clem LW and Miller NW (1998) Mitogen and growth factor-induced activation of a STAT-like molecule in channel catfish lymphoid cells. Mol Immunol 35:127-136.
Sohm F, Pezet A, Sandra O, Prunet P, de Luze A and Edery M (1998) Activation of gene transcription by tilapia prolactin variants tiPRL188 and tiPRL177. FEBS Lett 438:119-123.

Sotiropoulos A, Moutoussamy S, Renaudie F, Clauss M, Kayser C, Gouilleux F, Kelly PA and Finidori J (1996) Differential activation of Stat 3 and Stat5 by distinct regions of the growth hormone receptor. Mol Endocrinol 10:998-1009.

Storz P, Döppler H, Horn-Müller J, Groner B, Pfizenmaier K and Müller G (1999) A cellular reporter assay to monitor insulin receptor kinase activity based on STAT5-dependent luciferase gene expression. Anal Biochem 276:97-104.

Takeda K and Akira S (2000) STAT family of transcription factors in cytokine-mediated biological responses. Cytokine Growth FR 11:199-207.

von Laue S, Finidori J, Maamra M, Shen X-Y, Justice S, Dobson PRM and Ross RJM (2000) Stimulation of endogenous GH and interleukin-6 receptors selectively activates different Jaks and Stats, with a Stat5 specific synergistic effect of dexamethasone. J Endocrinol 165:301-311.

Yoshimura A (1998) The CIS family: negative regulators of JAK-STAT signaling. Cytokine Growth FR 9:197-204. 